Article

\title{
Improving the Damping Properties of Nanocomposites by Monodispersed Hybrid POSS Nanoparticles: Preparation and Mechanisms
}

\author{
Wei Wei, Yingjun Zhang, Meihua Liu *, Yifan Zhang, Yuan Yin, Wojciech Stanislaw Gutowski \\ Pengyang Deng and Chunbai Zheng* \\ CAS Key Laboratory of High-Performace Synthetic Rubber and its Composite Materials, Changchun Institute of \\ Applied Chemistry, Renmin Street 5625, Changchun 130022, China; weiwei@ciac.ac.cn (W.W.); \\ zyj13125823573@163.com (Y.Z.); yfzhang@ciac.ac.cn (Y.Z.); yuany@ciac.ac.cn (Y.Y.); \\ voytek.gutowski@csiro.au (W.S.G.); pydeng@ciac.ac.cn (P.D.) \\ * Correspondence: liumh@ciac.ac.cn (M.L.); zhengcb@ciac.ac.cn (C.Z.)
}

Received: 3 April 2019; Accepted: 6 April 2019; Published: 9 April 2019

\begin{abstract}
In this work, a series of heptaphenyl siloxane trisilanol/polyhedral oligomeric silsesquioxane ( $\mathrm{T}_{7}$-POSS) modified by polyols with different molecular weights were synthesized into liquid-like nanoparticle-organic hybrid materials using the grafted-from method. All grafted POSS nanoparticles changed from solid powders to liquid at room temperature. Polyurethane (PU) nanocomposites with POSS contents ranging from 1.75 to $9.72 \mathrm{wt} \%$ were prepared from these liquefied polyols-terminated POSS with polyepichlorohydrin (POSS-PECH). Transmission electron microscopy (TEM), scanning electron microscopy (SEM) and energy dispersive spectroscopy (EDS) were used to characterize the morphology of the POSS-PECH/PU nanocomposites. The results showed that the polyol-terminated POSS particles overcame the nanoagglomeration effect and evenly disperse in the polymeric matrix. The damping factor $(\tan \delta)$ of resultant nanocomposites increased from 0.90 to 1.16, while the glass transition temperature decreased from 15.8 to $9.4{ }^{\circ} \mathrm{C}$ when POSS contents increased from 0 to $9.75 \mathrm{wt} \%$. The gel content, tensile strength and Fourier transform infrared (FTIR) analyses demonstrated that the molecular thermal movement ability of the polyurethane (PU) matrix increased with increasing POSS hybrid content. Therefore, the improvement of the damping properties of the composites was mainly due to the friction-related losses occurring in the interface region between the nanoparticles and the matrix.
\end{abstract}

Keywords: monodisperse; nanocomposites; damping; POSS; liquefied

\section{Introduction}

In recent decades, nanocomposites have been intensely investigated by academy and industry researchers in the field of new materials development. A large number of nanocomposites have been successfully developed and applied, becoming the key driving force for the rapid development of advanced materials for applications in aviation, aerospace, transportation and energy technologies [1-8].

Nanocomposites often exhibit excellent strength, modulus of elasticity and toughness due to the reinforcement effects of nanofillers. In these commodity engineering applications, traditional theories of polymer mechanics are usually effective in predicting and guiding the static elastic properties of composites.

It is well known that the viscous properties of polymer composites can be expressed by the loss function known as 'tangent delta' ( $\tan \delta$ ), which is attributed to 1) intra-molecular friction and 
molecular relaxation, 2) friction between the polymer chain and filler, 3) friction between adjacent filler particles, and 4) flexibility of the polymer chain. The value of $\tan \delta$ is mainly determined by its viscoelastic behavior in the glass temperature $\left(T_{g}\right)$ transitional region. In this region, macromolecule chain segments tend to vibrate in phase with external vibrations. If numerous types of interactions exist between the polymer and filler, a broader $\tan \delta \operatorname{transition~region~would~be~desirable.~The~higher~}$ the internal friction, the higher the $\tan \delta$ value and the broader the transition region will be; thus, excellent energy dissipation (damping) performance of such composites will be observed [9-14]. However, increasing the strength and modulus of elasticity of nanocomposites usually leads to a decrease in damping properties. Researchers active in this field believe that this is because high modulus nanofillers (especially inorganic nanofillers) restrict the thermal movement of the chains in the polymer matrix.

Since 2005, many theoretical studies have demonstrated that fracturing (detaching) molecular chains from the surface of nanofillers can cause changes in conformational entropy. The associated mechanical energy loss is transformed into heat energy [15-20]. This implies that the larger the effective interface region between polymer chains and nanofillers, the greater the damping capacity of composites to attenuate vibrations or noise. As far as we know, no studies to date have shown that the damping properties of nanocomposites would continuously improve with the increase of nanofillers in addition to the matrix, although numerous studies have demonstrated that the uniform distribution of nanosized filler particles in the polymer matrix leads to reasonably good interfacial bonding strength [21-25]. This may be due to the serious nanoagglomeration effect in traditional nanocomposites, which leads to a decrease in the area of the interface region with the increase of nanofillers.

In this study, solid $\mathrm{T}_{7}$-POSS particles were liquefied by polyepichlorohydrin (PECH) oligomer grafted by a graft-from method. POSS-PECH/polyurethane (PU) nanocomposites, all exhibiting homogeneous morphology of monodispersed POSS nanocores in the PU matrix were then fabricated and characterized. Their damping performance is starkly contrasting that observed in traditional silicon dioxide $\left(\mathrm{SiO}_{2}\right), \mathrm{T}_{7}$-POSS or $\mathrm{T}_{8}$-POSS composites. The mobility of PU chain segments increases with the content of POSS-PECH. The observed high $\tan \delta$ and broad transition regions were attributed to increased internal friction and other interactions between the polymer chain and surface-modified POSS filler.

\section{Materials and Methods}

\subsection{Materials}

PECH was synthesized from ethylene glycol with epichlorohydrin (ECH) used as the monomer and boron trifluoride etherate $\left(\mathrm{BF}_{3}\right.$-etherate) as the catalyst (laboratory grade). Castor oil was purchased from Tongliao Chemical Reagent Factory (Tongliao, Neimenggu, China). Polyaryl polymethylene isocyanate (PAPI) was provided by Bayer (NCO 30.5-32.0 wt \%, Leverkusen, Germany). $\mathrm{T}_{7}$-POSS was received from Hybrid Plastics, CA (Hattiesburg, MS, USA).

\subsection{Synthesis of POSS-PECH}

The synthesis route of POSS-PECH utilizing $\mathrm{T}_{7}$-POSS as the starting agent is shown in Figure 1. The ring-opening polymerization of epichlorohydrin was carried out in a $500 \mathrm{~mL}$ triple-neck flask equipped with a mechanical paddle, a temperature gauge and a dropping funnel. To the stirred solution of $\mathrm{T}_{7}$-POSS in dichloromethane, a precisely measured volume of boron trifluoride ether was then added as a catalyst at room temperature, and stirring was continued for $30 \mathrm{~min}$. The reaction flask temperature was brought down to $18{ }^{\circ} \mathrm{C}$ using ice. Epichlorohydrin was then slowly added to the reaction mixture over a period of $4 \mathrm{~h}$ using a dropping funnel. The reaction mixture was then stirred for $4 \mathrm{~h}$ at $40^{\circ} \mathrm{C}$. The synthesized polymer solution was subsequently treated with saturated $\mathrm{NaHCO}_{3}$ solution and distilled water to remove unreacted diol and the initiator when the reaction was 
completed. The reaction mixture was then filtrated, and the solvent and small-molecule compounds were removed by vacuum distillation at $110{ }^{\circ} \mathrm{C}$ for $2 \mathrm{~h}$, yielding a viscous fluid (see Figure 2b). Thus, four synthesized POSS-PECH compounds with different molecular weights were produced and are listed in Table 1.
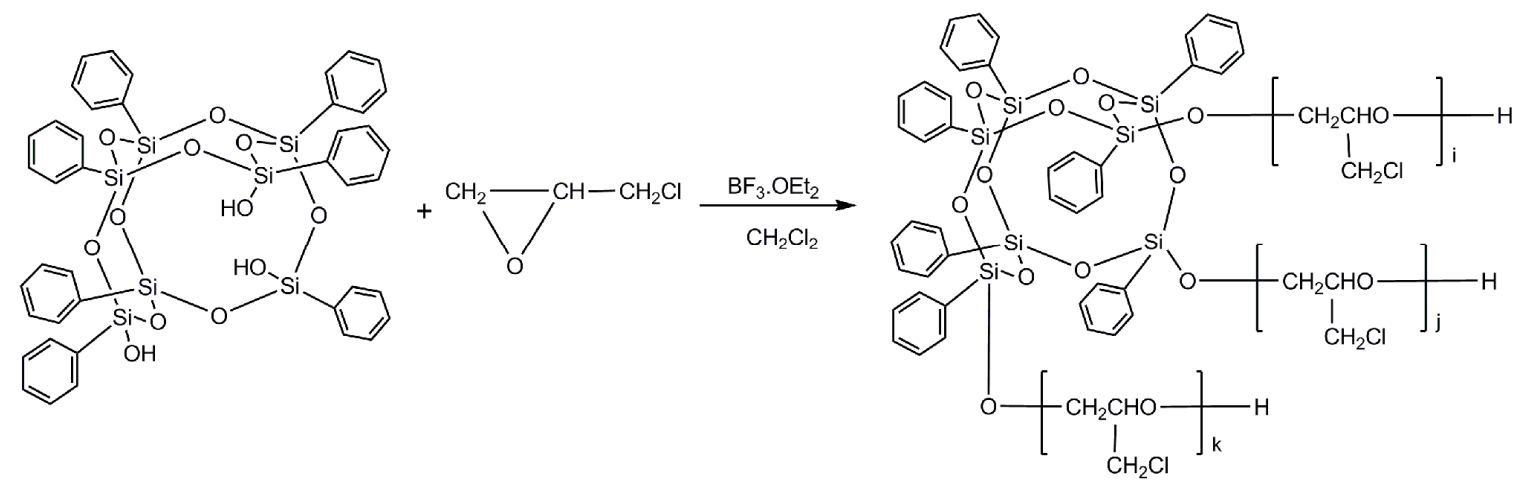

Figure 1. Synthetic route of POSS-PECH.

Table 1. Feed molar ratio of POSS-PECH with different molecular weights.

\begin{tabular}{ccccc}
\hline PECH Samples & $\mathbf{T}_{\mathbf{7}}$-POSS (mol) & ECH (mol) & $\begin{array}{c}\mathbf{B F}_{\mathbf{3}} \cdot \mathbf{O E t}_{\mathbf{2}} \\
\mathbf{( \mathbf { m o l } )}\end{array}$ & Mw of POSS-PECH \\
\hline POSS-1 & 1 & 10 & 0.6 & 1573 \\
POSS-2 & 1 & 25 & 0.6 & 2762 \\
POSS-3 & 1 & 40 & 0.6 & 3533 \\
POSS-4 & 1 & 55 & 0.6 & 4136 \\
\hline
\end{tabular}

\subsection{Sample Preparation}

POSS-based polyurethane formulations (see Table 2 for details) were prepared by a one-step method. Pre-weighted quantities of POSS-PECH, PECH and castor oil were added to a Teflon cup and then placed in the oven preheated to $85^{\circ} \mathrm{C}$ for $30 \mathrm{~min}$. The melt curing agent for the PUs, PAPI, was then added and mechanically stirred to achieve homogeneity. The resultant mixture was degassed under vacuum, poured into preheated glass molds coated with a mold release agent and then cured at $100{ }^{\circ} \mathrm{C}$ for $24 \mathrm{~h}$. In this study, a series of polyurethane samples was prepared by changing the isocyanate index $(\mathrm{R})$ and the addition of POSS-PECH.

Table 2. Formulations of PU compositions

\begin{tabular}{|c|c|c|c|c|c|c|c|}
\hline PU Samples & $\begin{array}{c}\text { Castor Oil } \\
\text { (g) }\end{array}$ & $\begin{array}{c}\text { PECH } \\
\text { (g) }\end{array}$ & $\begin{array}{c}\text { POSS1 } \\
\text { (g) }\end{array}$ & $\begin{array}{c}\text { POSS2 } \\
\text { (g) }\end{array}$ & $\begin{array}{c}\text { POSS3 } \\
\text { (g) }\end{array}$ & $\begin{array}{c}\text { POSS4 } \\
\text { (g) }\end{array}$ & $\begin{array}{c}\text { PAPI } \\
\text { (g) }\end{array}$ \\
\hline Pure-PECH/PU & 10 & 10 & & & & & 6.09 \\
\hline 1.75\%-POSS1/PU & 10 & 10 & 2 & & & & 6.28 \\
\hline $4.54 \%-P O S S 1 / \mathrm{PU}$ & 10 & 10 & 6 & & & & 6.66 \\
\hline 7.57\%-POSS1/PU & 10 & 10 & 12 & & & & 7.22 \\
\hline $9.72 \%-P O S S 1 / P U$ & 10 & 10 & 18 & & & & 7.79 \\
\hline $5.55 \%-P O S S 2 / P U$ & 10 & 10 & & 18 & & & 7.68 \\
\hline $4.35 \%-P O S S 3 / P U$ & 10 & 10 & & & 18 & & 7.60 \\
\hline 3.74\%-POSS4/PU & 10 & 10 & & & & 18 & 7.48 \\
\hline POSS1/PU-0.90 & 10 & 10 & 18 & & & & 6.67 \\
\hline POSS1/PU-0.95 & 10 & 10 & 18 & & & & 7.05 \\
\hline POSS1/PU-1.00 & 10 & 10 & 18 & & & & 7.42 \\
\hline POSS1/PU-1.05 & 10 & 10 & 18 & & & & 7.79 \\
\hline
\end{tabular}




\subsection{Gel Extraction Experiments}

Samples weighing approximately $0.2 \mathrm{~g}$, were cut into pieces and weighed with an accuracy of \pm 0.5 $\mathrm{mg}$, and designated $\mathrm{W}_{0}$. They were covered with filter paper, placed on a nickel mesh, and their total weight was determined as $\mathrm{W}_{1}$. These were placed in a triple-neck flask, refluxed with dichloromethane for $48 \mathrm{~h}$ with the solvent changed every $24 \mathrm{~h}$, then washed with ethanol and placed in an oven until constant weight, $\mathrm{W}_{2}$, was reached. The gel content, G [\%], was determined using the following formula:

$$
\mathrm{G}=\left[1-\left(\mathrm{W}_{1}-\mathrm{W}_{2}\right) / \mathrm{W}_{0}\right] \times 100 \%
$$

\subsection{Characterization}

Dynamic mechanical analysis (DMA) measurements were performed on a DMA +450 analyzer (01db-Metravib, Paris, France). The PU film was cut into $4 \times 1 \times 0.2 \mathrm{~cm}$ rectangular strips and tested in tensile mode over the temperature range from -40 to $60^{\circ} \mathrm{C}$. The heating rate was fixed at $3{ }^{\circ} \mathrm{C} / \mathrm{min}$. The frequencies were and $0.5,1,3$ and $5 \mathrm{~Hz}$ respectively.

FTIR spectra were recorded with a VERTEX 70 spectrometer (Bruker Daltonics Inc., Billerica, MA, USA) in the range of $4000-500 \mathrm{~cm}^{-1}$ at a resolution of $4 \mathrm{~cm}^{-1}$; eight scans were collected per sample.

TEM images were recorded with a Tecnai G2 transmission electron microscope with $200 \mathrm{kV}$ accelerating voltage (FEI Co., Hillsboro, OR, USA). Specimens with a thickness of ca. $50 \mathrm{~nm}$ were prepared by ultra-cryomicrotomy at $-35^{\circ} \mathrm{C}$ using a Leica UCT microtome.

SEM and EDS images were taken using a Philips XL-30 FEG (Amsterdam, The Netherlands). The samples were broken in liquid nitrogen, and all samples were coated with an ultrathin Au film by high-vacuum evaporation before observing the cross sections. At least three sections were observed to show a representative image.

Tensile strength was determined by universal testing machine INSTRON 1121 (INSTREAM Corporation, Boston, MA, USA), according to GB/T1040.1-2006. The samples (dumbbell shape, $50 \times 2 \mathrm{~mm}$, gauge length $4 \mathrm{~mm}$ ) were tested at a strain rate of $100 \mathrm{~mm} / \mathrm{min}$.

Gel permeation chromatography (GPC) analyses were carried out using PL-GPC-120 from Polymer Laboratories (Lanarkshire, UK). The solvent used was DMF at $80{ }^{\circ} \mathrm{C}$ with a flow rate of $1.0 \mathrm{~mL} / \mathrm{min}$.

${ }^{1} \mathrm{H}-\mathrm{NMR}$ and ${ }^{13} \mathrm{C}$-NMR analyses were conducted on a BRUKER $400 \mathrm{MHz}$ NMR spectrometer (Bruker Daltonics Inc.) in $\mathrm{CDCl}_{3}$ solvent with tetramethylsilane as the internal standard.

\section{Results}

\subsection{Chemical Structural Analysis of POSS-PECH}

At room temperature, $\mathrm{T}_{7}$-POSS transformed from the solid to liquid state after polymerization (see Figure 2a,b). The FTIR spectrum of POSS-PECH presented in Figure 2 shows a peak at approximately $3442 \mathrm{~cm}^{-1}$ that was assigned to the $\mathrm{O}-\mathrm{H}$ stretching band. The peaks at 2958 and $2876 \mathrm{~cm}^{-1}$ represent a $\mathrm{C}-\mathrm{H}$ stretching band. The characteristic peaks at approximately 1430, 1130 and $747 \mathrm{~cm}^{-1}$ correspond to deforming of the $\mathrm{C}-\mathrm{H}, \mathrm{C}-\mathrm{O}-\mathrm{C}$ stretching band and $\mathrm{C}-\mathrm{Cl}$ stretching band, respectively. The peak at $1596 \mathrm{~cm}^{-1}$ is characteristic of phenyl on POSS substituents.

NMR spectra were useful for determining the material composition. Figure 2 presents ${ }^{1} \mathrm{H}-\mathrm{NMR}$ (2d) and ${ }^{13} \mathrm{C}-\mathrm{NMR}(2 \mathrm{e})$ spectra of POSS-PECH. The peaks at 3.62, 3.72 and $3.99 \mathrm{ppm}$ in Figure $2 \mathrm{~d}$ correspond to the main chain hydrogen atom of POSS-PECH. The areas of signals at 7.10-7.95 ppm can be related to phenyl on POSS substituents. The ${ }^{13} \mathrm{C}-\mathrm{NMR}$ spectrum of POSS-PECH is shown in Figure 2e. The assignment of individual peaks is as follows: $\delta\left(\mathrm{CH}_{2}-\mathrm{Cl}\right)$ is at $43.13-45.07 \mathrm{ppm}$, $\delta\left(\mathrm{O}-\mathrm{CH}_{2}\right)$ is at $68.98-71.13 \mathrm{ppm}, \delta(\mathrm{O}-\mathrm{CH})$ is at $78.60-78.98 \mathrm{ppm}$, and $\delta($ phenyl)is at $127.53-133.92 \mathrm{ppm}$.

The above analyses of FTIR and NMR spectra prove that the synthesized product was an oligomer of hydroxyl-terminated polyepichlorohydrin grafted to the POSS structure. The molecular weights of alternative POSS-PECH samples that were synthesized are shown in Table 3. The hydroxyl value of 
POSS-PECH, as seen in Table 4 and measured by the acetic anhydride-pyridine method, decreases with increasing molecular weight.
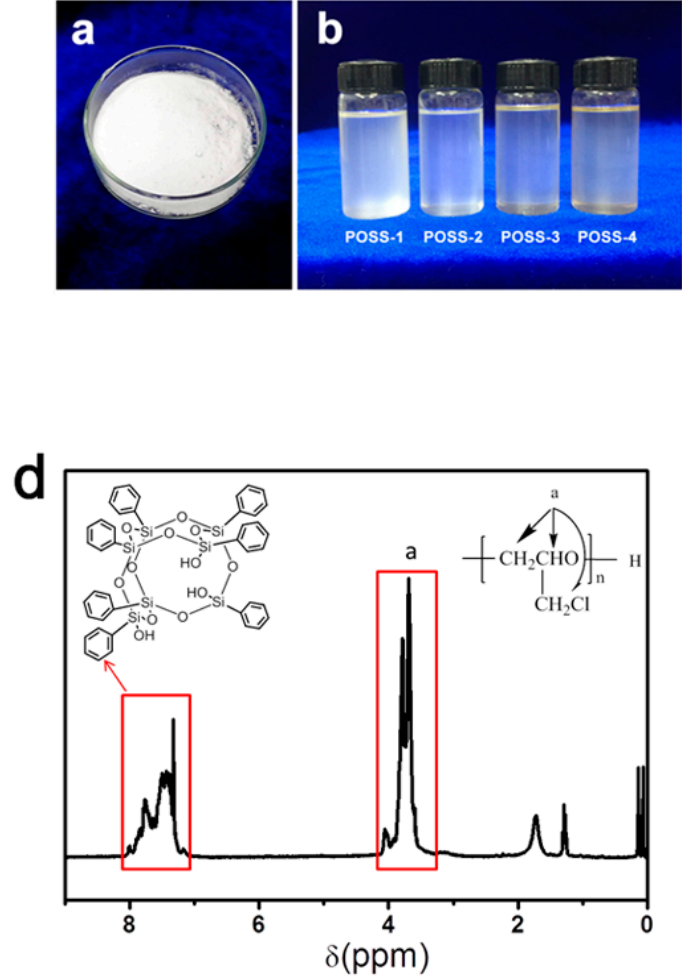

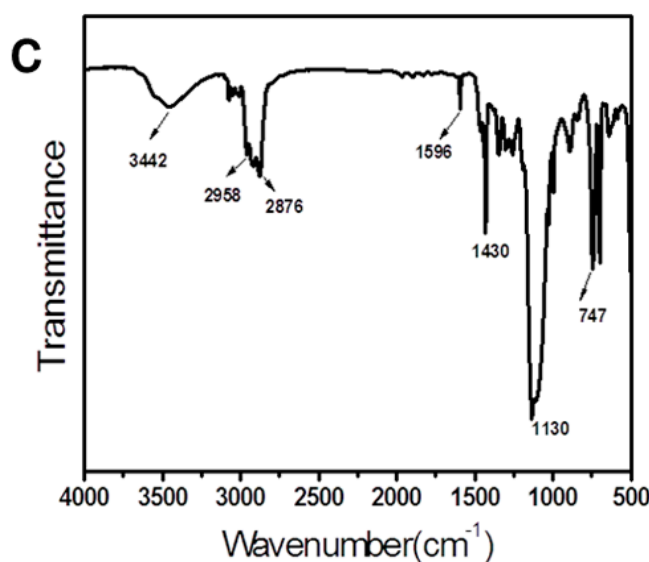

e

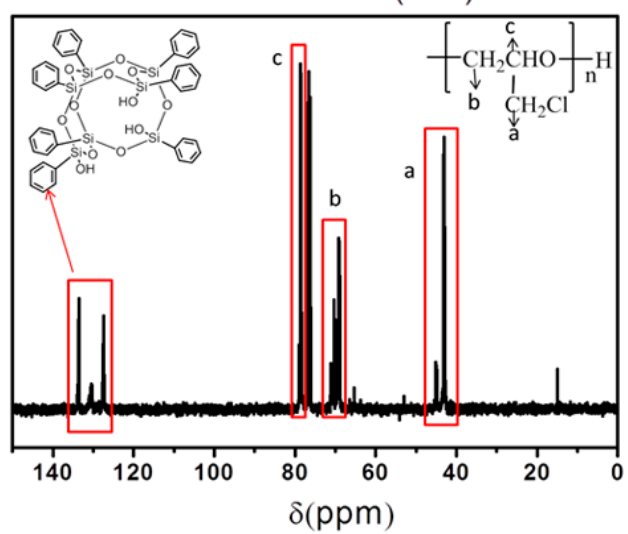

Figure 2. (a) Photograph of $\mathrm{T}_{7}$-POSS before liquefaction. (b) Photograph of $\mathrm{T}_{7}$-POSS after liquefaction. (c) FTIR spectra of POSS-PECH. (d) ${ }^{1} \mathrm{H}$ NMR spectra of POSS-PECH. (e) ${ }^{13} \mathrm{C}$ NMR spectra of POSS-PECH.

Table 3. Summary of gel permeation chromatography (GPC) data of POSS-PECH.

\begin{tabular}{cccccccc}
\hline PECH Samples & $\mathbf{M p}$ & $\mathbf{M n}$ & $\mathbf{M v}$ & $\mathbf{M w}$ & $\mathbf{M z}$ & $\mathbf{M z}+\mathbf{1}$ & $\mathbf{P D}$ \\
\hline POSS-1 & 1607 & 1348 & 1538 & 1573 & 1812 & 2057 & 1.1669 \\
POSS-2 & 2120 & 1960 & 2628 & 2762 & 3737 & 4698 & 1.4092 \\
POSS-3 & 3841 & 2439 & 3365 & 3533 & 4689 & 5730 & 1.4485 \\
POSS-4 & 4871 & 2614 & 3894 & 4136 & 5849 & 7420 & 1.5822 \\
\hline
\end{tabular}

Table 4. Hydroxyl value of POSS-PECH with different molecular weights.

\begin{tabular}{cc}
\hline PECH Samples & Hydroxyl Value (mol/g) \\
\hline POSS-1 & $6.64 \times 10^{-4}$ \\
POSS-2 & $6.20 \times 10^{-4}$ \\
POSS-3 & $5.90 \times 10^{-4}$ \\
POSS-4 & $5.42 \times 10^{-4}$ \\
\hline
\end{tabular}

\subsection{Structure and Phase Morphology Analysis of POSS-Based Polyurethane Nanocomposites}

To investigate the chemical structure of the PUs with respect to various contents of POSS-PECH and pure-PECH, their FTIR spectra were obtained and are shown in Figure 3a. The absorption peak of the $-\mathrm{NH}$ bond appears at $3329 \mathrm{~cm}^{-1}$, and the stretching vibration peak of the $\mathrm{C}=\mathrm{O}$ bond in the urethane bond appears at $1727 \mathrm{~cm}^{-1}$. The characteristic absorption peak of the ether bond $\mathrm{C}-\mathrm{O}-\mathrm{C}$ appears at approximately $1112 \mathrm{~cm}^{-1}$. These three features indicate that the characteristic functional 
group of polyurethane carbamate, NHCOO, was successfully formed. The absence of an absorption peak from isocyanate groups at $2270 \mathrm{~cm}^{-1}$ reflects the complete curing reaction.
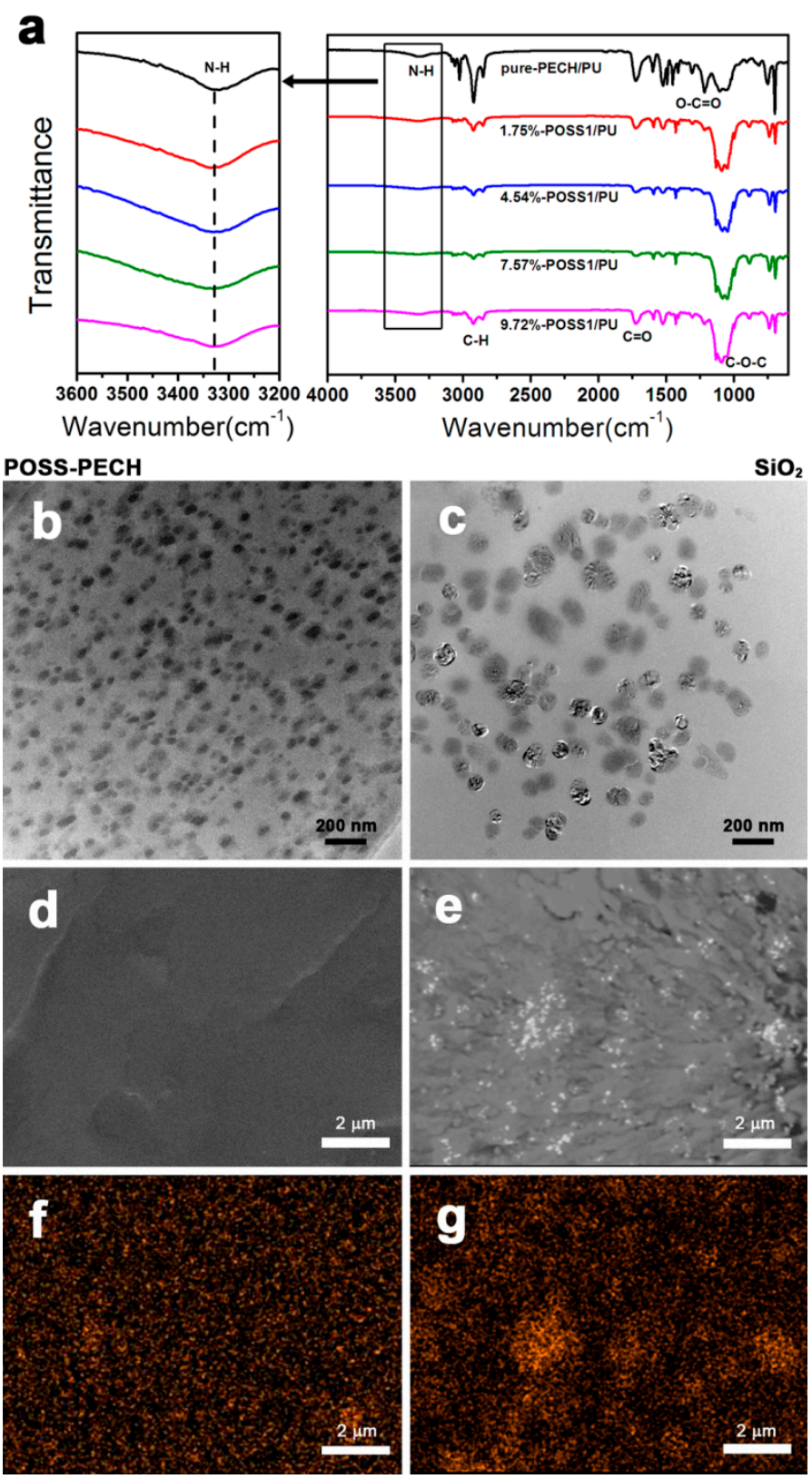

Figure 3. (a) FTIR spectra of PUs with different POSS contents. (b) TEM images of $9.72 \%$ POSS-modified PU. (c) TEM images of $9.74 \% \mathrm{SiO}_{2}$-modified PU. (d) SEM images of 9.72\% POSS-modified PU. (e) SEM images of $1.96 \% \mathrm{SiO}_{2}$-modified PU. (f) Element mapping images of Si 9.72\% POSS-modified PU. (g) Element mapping images of $\mathrm{Si} 1.96 \% \mathrm{SiO}_{2}$-modified PU.

The dispersion of POSS nanoparticles in the PU composites was observed by TEM. The results show that even when the POSS content reached $9.72 \mathrm{wt} \%$ of the total weight of the composites, no POSS particles were agglomerated, and all were uniformly distributed in the composite resin with a nearly identical size. The fracture surface of the composite presented in Figure $3 \mathrm{~d}$ demonstrates a homogeneous morphology with no phase separation observed between the POSS particles and matrix resin. The results of EDS (see Figure $3 \mathrm{f}$ ) are in good agreement with those of TEM; that is, the silicon elements in the POSS cage are uniformly distributed throughout the cross section of the sample, with no obvious agglomeration observed. 
The above results are substantially different from the traditional morphology and structure of nano- $\mathrm{SiO}_{2}-\mathrm{PU}$ composites. Figure $3 \mathrm{c}$ shows a typical TEM micrograph of nanocomposites comprising nanosilica in the PU matrix. The results demonstrate that even if the content of nano-SiO $\mathrm{S}_{2}$ is only $1.96 \mathrm{wt} \%$ of the total composite weight, agglomeration always occurs, and the cluster size after agglomeration is between 40 and $150 \mathrm{~nm}$. It is also observed that the particle dispersion within clusters is not uniform. Consequently, the morphology of fracture surfaces in silica-PU composites (Figure 3e) is notably different from those containing modified POSS. The sharp interface between agglomerated $\mathrm{SiO}_{2}$ particles and matrix resin is clearly visible, with phase separation consistent with the agglomeration and non-uniform dispersion of elemental silicon clearly shown in EDS in Figure 3g.

The above results show that the PECH oligomeric chain grafted onto the POSS cage effectively changed the particle surface structure, overcoming the agglomeration problem of POSS particles and facilitating uniform dispersion of POSS inorganic cages within the polyurethane polymer in a monodispersed state [26,27].

\subsection{Damping Properties}

The dynamic properties of materials, including their damping performance, are commonly studied by DMA, in which the storage modulus ( $E^{\prime}$ ) and the loss modulus ( $\left.E^{\prime \prime}\right)$ of the sample under an oscillating load are monitored against time, temperature and frequency of the oscillation. These moduli change with frequency and temperature as the molecular motions within the polymer change. The ratio of $E^{\prime} / E^{\prime \prime}=\tan \delta$, which defines the inherent energy dissipation ability of the material, is commonly used to characterize its damping ability. A high $\tan \delta$ value and large temperature range indicates excellent damping performance of the system.

In general, the energy dissipation reaches a maximum near the glass transition temperature of the polymer $\left(T_{\mathrm{g}}\right)$ because in this regime, without considering the chemical structure of the molecular chain, the following molecular chain motions simultaneously transform mechanical energy into thermal energy. When movable molecular chains are relatively short, under the action of external strain, there will be a large conformational change leading to the conformational entropy of materials. In the glassy state, the distance between chains is short and the interaction between chains is strong. Therefore, when the free chains move, the interaction force between the molecules that needs to be overcome is high. When the free chains move relative to each other, the internal friction between the molecular chains that needs to be overcome is large, and the internal friction between the molecular chain and the filler is also large.

\subsubsection{Effect of POSS1 Content on the Damping Properties of PU Composites}

The effect of POSS1 content on tan $\delta$ of PU nanocomposites is shown in Figure 4a and Table 5. The transition peaks in the DMA spectra of PU nanocomposites with different POSS1 contents indicate that POSS-PECH has good compatibility with the matrix material. Compared with pure polyurethane polymer, the $\tan \delta$ of POSS-based PU nanocomposites increased from 0.91 to 1.16 with the increasing POSS content (an increase of $27.5 \%$ ), whereas the damping temperature range ( $\tan \delta>0.3$ ) increased from $\Delta T=34.4$ to $44.0^{\circ} \mathrm{C}$, thus increasing by $28.1 \%$. Meanwhile, the $T_{\mathrm{g}}$ and the initial temperature of the damping temperature range $\left(T_{1}\right)$ of the PU-POSS nanocomposites gradually decreased respectively: $T_{\mathrm{g}}$ to $9.4^{\circ} \mathrm{C}$ from $15.8^{\circ} \mathrm{C}$ and $T_{1}$ to $-6.9^{\circ} \mathrm{C}$ from $-1.1{ }^{\circ} \mathrm{C}$. These results demonstrate that monodispersed nano-POSS particles effectively improved the damping properties of the composites, importantly demonstrating that the increased POSS content did not restrict the thermal mobility of molecular chains. 

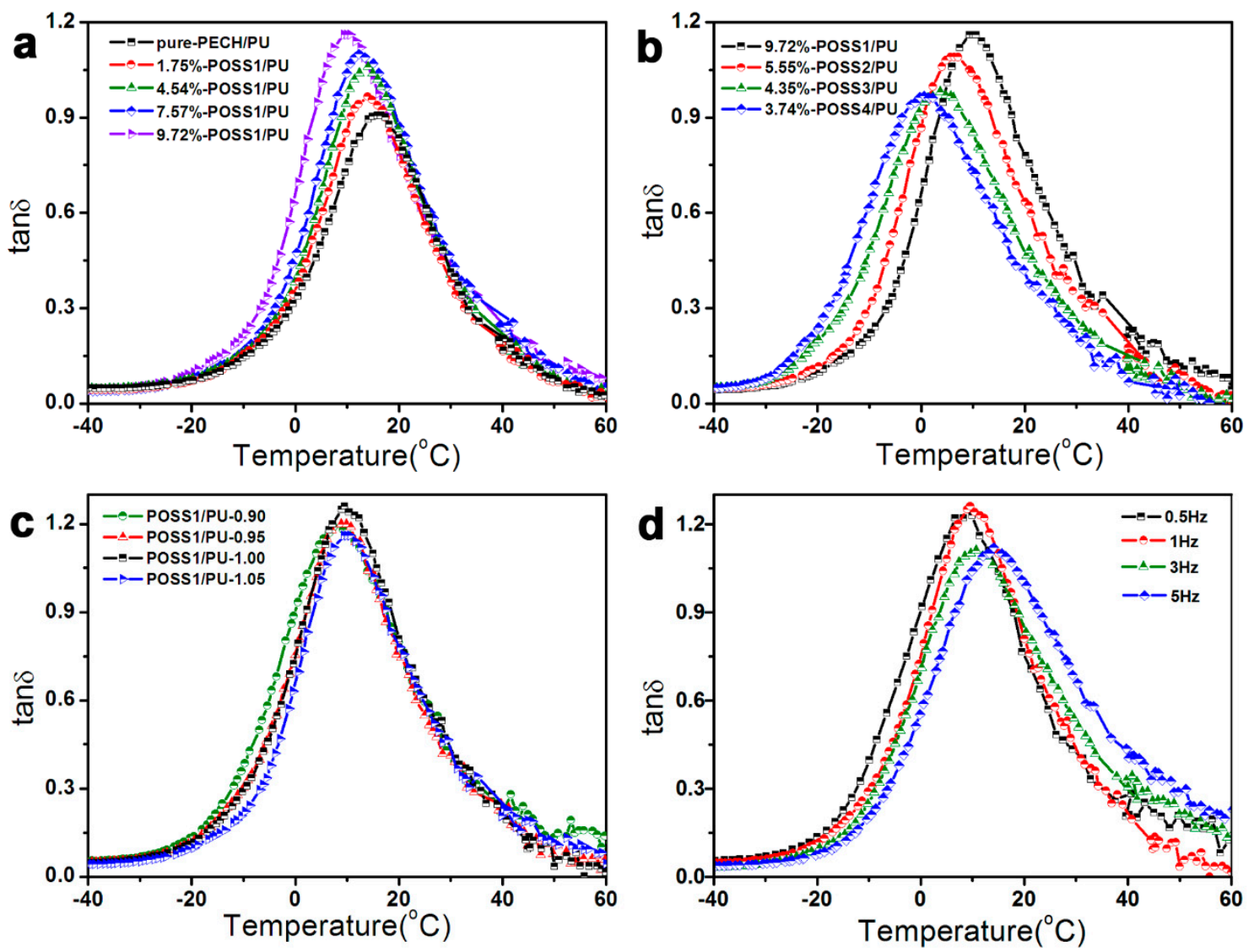

Figure 4. This loss factor $(\tan \delta$ ) curves vs temperature for: (a) The neat PU matrix and PUs with different POSS contents (POSS-PECH with same molecular weight), (b) PUs with different POSS contents (POSS-PECH with different molecular weights), (c) PUs with different isocyanate indexes (R) and (d) PUs response to different strain frequencies.

Table 5. Summary of DMA data of PUs with different POSS contents (POSS-PECH with same molecular weight).

\begin{tabular}{lcccccc}
\hline \multirow{2}{*}{ PU Samples } & $\begin{array}{c}\text { Inorganic Core } \\
\text { Content (\%) }\end{array}$ & $\tan \delta \boldsymbol{T}_{\mathbf{g}} /{ }^{\circ} \mathbf{C}$ & \multicolumn{3}{c}{ Damping Temperature Field (tan $\delta>\mathbf{0 . 3})$} \\
\cline { 5 - 7 } & & & & $\boldsymbol{T}_{\mathbf{1}} /{ }^{\circ} \mathbf{C}$ & $\boldsymbol{T}_{\mathbf{2}} /{ }^{\circ} \mathbf{C}$ & $\boldsymbol{\Delta} \boldsymbol{T}^{\circ} \mathbf{C}$ \\
\hline Pure-PECH/PU & 0 & 0.9064 & 15.8 & -1.1 & 33.3 & 34.4 \\
1.75\%-POSS1/PU & 1.75 & 0.9659 & 14.0 & -2.0 & 32.6 & 34.6 \\
$4.54 \%-P O S S 1 / P U$ & 4.54 & 1.058 & 14.1 & -2.7 & 34.2 & 36.9 \\
$7.57 \%-P O S S 1 / P U$ & 7.57 & 1.099 & 12.3 & -4.0 & 37.4 & 41.4 \\
$9.72 \%-P O S S 1 / P U$ & 9.72 & 1.164 & 9.4 & -6.9 & 37.1 & 44.0 \\
\hline
\end{tabular}

$\mathrm{M}_{\mathrm{W}}=1573, \mathrm{R}=1.05$, the percentage content is the content of inorganic POSS nanoparticles. $T_{1}$ is the starting temperature of $\tan \delta>0.3$, and $T_{2}$ is the terminating temperature of $\tan \delta>0.3$.

\subsubsection{Effect of Molecular Weight Change of POSS-PECH on Damping Property of Composites}

The effects of POSS-PECH polyols with different molecular weights on the damping properties of nanocomposites were investigated, as shown in Figure $4 \mathrm{~b}$ and Table 6 . The results demonstrate that the $\tan \delta$ and $\Delta T$ of all POSS-PECH composites were higher than those of the unmodified bulk material. The $\tan \delta$ decreased gradually with increasing molecular weight of POSS-PECH; although the $\Delta T$ was almost unchanged, the $T_{1}$ of the damping temperature range decreased gradually with increasing molecular weight.

At the same time, the $T_{\mathrm{g}}$ of composites gradually decreased with increasing molecular weight of POSS-PECH. The initial $T_{\mathrm{g}}$ was $15.8^{\circ} \mathrm{C}$ for pure PU-PECH and decreased to $0.6^{\circ} \mathrm{C}$ for composites with POSS4 modified with $\mathrm{PECH}$ and $\mathrm{a}_{\mathrm{w}}=4136$; this is the highest range for the materials investigated 
in this work. This trend highlights the fact that the size of the interfacial region surrounding the POSS-PECH nanoparticles appears to be a key factor controlling the viscous properties of the system and thus the composite damping properties.

Table 6. Summary of DMA data of PUs with different molecular weights of POSS-PECH.

\begin{tabular}{|c|c|c|c|c|c|c|}
\hline \multirow{2}{*}{ PU Samples } & \multirow{2}{*}{$\begin{array}{l}\text { Inorganic Core } \\
\text { Content }(\%)\end{array}$} & \multirow{2}{*}{\multicolumn{2}{|c|}{$\tan \delta \mathrm{T}_{\mathrm{g}} /{ }^{\circ} \mathrm{C}$}} & \multicolumn{3}{|c|}{ Damping Temperature Field $(\tan \delta>0.3)$} \\
\hline & & & & $T_{1} /{ }^{\circ} \mathrm{C}$ & $T_{2} /{ }^{\circ} \mathrm{C}$ & $\Delta T^{\circ} \mathrm{C}$ \\
\hline Pure & 0 & 0.964 & 15.8 & -1.1 & 33.3 & 34.4 \\
\hline $\begin{array}{c}\text { PECH/PU } \\
\text { 9.72\%-POSS1/PU }\end{array}$ & 9.72 & 1.164 & $\begin{array}{c}10.0 \\
9.4\end{array}$ & -6.9 & 37.1 & 44.0 \\
\hline $5.55 \%-P O S S 2 / \mathrm{PU}$ & 5.55 & 1.091 & 6.5 & -10.3 & 34.0 & 44.3 \\
\hline 4.35\%-POSS3/PU & 4.35 & 0.9813 & 3.7 & -15.1 & 28.2 & 43.3 \\
\hline 3.74\%-POSS4/PU & 3.74 & 0.9681 & 0.6 & -18.1 & 25.9 & 44.0 \\
\hline
\end{tabular}

$T_{1}$ is the starting temperature of $\tan \delta>0.3$, and $T_{2}$ is the terminating temperature of $\tan \delta>0.3$.

\subsubsection{Effect of $R$ Value on Damping Property of Polyurethane Polymer}

The $\mathrm{R}$ value is the molar ratio of isocyanate groups $(-\mathrm{NCO})$ to hydroxyl groups $(-\mathrm{OH})$. By adjusting the $\mathrm{R}$ value, the crosslinking density and structure of composites can be custom-tailored, and hence, it was anticipated that the damping properties could also be adjusted. The numerical data in Table 7 and those graphically presented in Figure 4c provide insight into the damping properties of POSS-based polyurethane composites with different R-values and almost constant contents of POSS nanoparticles. The results demonstrate that the damping properties of POSS-based PU nanocomposites, that is, the $\tan \delta$ and $\Delta T$ were almost independent of the $R$ value. Only at $R=1.00$ was the loss factor $\tan \delta=1.26$, thus showing some improvement of damping properties. However, with the increase in the $\mathrm{R}$ value, the $\Delta T$ was shifted towards higher temperatures, that is, from $\left(-12.3 \leftrightarrow+35.8{ }^{\circ} \mathrm{C}\right)$ to $\left(-6.9{ }^{\circ} \mathrm{C} \leftrightarrow+37.1^{\circ} \mathrm{C}\right)$. This is because the content of the hard segment increased slightly with the increase in $\mathrm{R}$ value, resulting in the $\Delta T$ moving towards a high temperature. These results also indicate that the improvement of the damping properties of POSS-PECH based nanocomposites is mainly due to the change in PECH-grafted POSS particle content.

Table 7. Summary of DMA data of PUs with different molecular weights of POSS-PECH.

\begin{tabular}{ccccccc}
\hline $\begin{array}{c}\text { PU Samples } \\
\text { [POSS/PU-R] }\end{array}$ & $\begin{array}{c}\text { Inorganic Core } \\
\text { Content (\%) }\end{array}$ & $\tan \delta \boldsymbol{T}_{\mathbf{g}} /{ }^{\circ} \mathbf{C}$ & \multicolumn{3}{c}{ Damping Temperature Field (tan $\delta>\mathbf{0 . 3})$} \\
\cline { 5 - 6 } & & & & $\boldsymbol{T}_{\mathbf{1}} /{ }^{\circ} \mathbf{C}$ & $\boldsymbol{T}_{\mathbf{2}} /{ }^{\circ} \mathbf{C}$ & $\Delta \boldsymbol{T}^{\circ} \mathbf{C}$ \\
\hline POSS1/PU-0.90 & 9.96 & 1.186 & 7.5 & -12.3 & 35.8 & 48.1 \\
POSS1/PU-0.95 & 9.88 & 1.201 & 9.6 & -10.4 & 33.6 & 44.0 \\
POSS1/PU-1.00 & 9.80 & 1.262 & 9.6 & -9.7 & 35.1 & 44.8 \\
POSS1/PU-1.05 & 9.72 & 1.164 & 9.4 & -6.9 & 37.1 & 44.0 \\
\hline
\end{tabular}

$T_{1}$ is the starting temperature of $\tan \delta>0.3$ and $T_{2}$ is the terminating temperature of $\tan \delta>0.3$.

\subsubsection{Effect of Different Testing Frequencies on Damping Property of Polyurethane Polymer}

The effects of different test frequencies on the damping properties of polyurethane polymers were analyzed using data sets presented in Figure $4 \mathrm{~d}$ and Table 8 . The results show that with increasing test frequency, the $\tan \delta$ of the polymer first increased and then decreased. The $T_{\mathrm{g}}$ gradually increased, the $\Delta T$ moved towards high temperature, and the range of $\tan \delta>0.3$ increased slightly. 
Table 8. Summary of DMA data of PUs with different test frequencies.

\begin{tabular}{cccccc}
\hline \multirow{2}{*}{ Test Frequency (Hz) } & \multirow{2}{*}{ Tan $\delta \boldsymbol{T}_{\mathbf{g}} /{ }^{\circ} \mathbf{C}$} & \multicolumn{3}{c}{ Damping Temperature Field $(\tan \delta>0.3)$} \\
\cline { 4 - 6 } & & & $\boldsymbol{T}_{\mathbf{1}} /{ }^{\circ} \mathbf{C}$ & $\boldsymbol{T}_{\mathbf{2}} /{ }^{\circ} \mathbf{C}$ & $\Delta \mathbf{T}^{\circ} \mathbf{C}$ \\
\hline 0.5 & 1.234 & 9.9 & -12.3 & 34.5 & 46.8 \\
1 & 1.262 & 9.6 & -9.7 & 35.1 & 44.8 \\
5 & 1.111 & 10.7 & -8.7 & 40.1 & 48.8 \\
5 & 1.119 & 14.1 & -6.8 & 48.5 & 55.3 \\
\hline
\end{tabular}

$\mathrm{M}_{\mathrm{W}}=1573, \mathrm{R}=1.05$, PU with $9.72 \%$ inorganic nanomaterials content was tested by DMA at different frequencies.

\section{Discussion}

The analysis of the results presented above yields the following information:

When the POSS nanoparticles surface-grafted with pendent chains of PECH are distributed in the polymer matrix in the form of a monodispersed phase, the damping properties of the nanocomposites increase with the increase the nano-POSS content. This effect is completely opposite to the performance of traditional nanocomposites, such as nano-SiO ${ }_{2}-\mathrm{PU}$ and unmodified POSS-PU composites (for details see Supplementary Materials), whose damping properties are presented in Table 9 and depicted in Figure 5. These results clearly demonstrate that increasing the nano- $\mathrm{SiO}_{2}$ content results in the deterioration of the damping properties of $\mathrm{SiO}_{2}-\mathrm{PU}$ nanocomposites. The $\tan \delta$ is shown to be gradually reduced by $25.3 \%$ from the initial value of $\tan \delta$ equal to 0.91 for the unmodified (pure PECH-PU) material to tan $\delta$ equal to 0.68 exhibited by the nano- $\mathrm{SiO}_{2}-\mathrm{PU}$ composite containing $9.74 \%$ of $\mathrm{SiO}_{2}$ nanoparticles. This loss function value equals only $50 \%$ of the damping capability of our composites, with POSS1-PU containing a similar concentration of surface-grafted POSS nanoparticles. The $\Delta T$ is almost unchanged compared with that related to the original material, but the $T_{1}$ and the $T_{\mathrm{g}}$ of the $\mathrm{SiO}_{2}$-composite system both increase with the increasing amount of silica.

A number of earlier studies $[28,29]$ have shown that the decrease in damping performance of traditional $\mathrm{SiO}_{2}-\mathrm{PU}$ composite systems is due to nanoparticles being dispersed in the soft matrix and acting as 'physical crosslinks', which limit the thermal movements of molecular chains in the soft matrix. These restrictions become stronger as the number of nanoparticles increases, and hence, the number of 'physical crosslinks' is increased. Consequently, any restrictions on the molecular thermal motion ability will lead to a decrease in the damping property of the composite material and an increase in $T_{1}$ and $T_{\mathrm{g}}$.

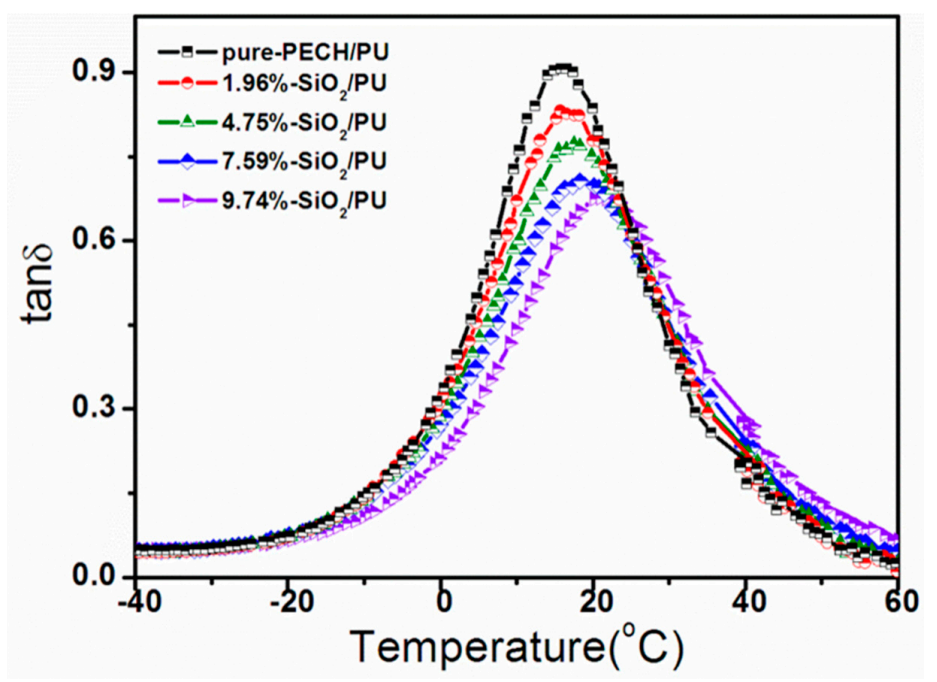

Figure 5. Loss factor $(\tan \delta$ ) curves vs temperature for PU composites with the addition of traditional nano-SiO 2 (0 to $9.74 \%)$ 
Table 9. Summary of DMA data of PU Composites with traditional nano- $\mathrm{SiO}_{2}$.

\begin{tabular}{|c|c|c|c|c|c|}
\hline \multirow{2}{*}{ PU Samples } & \multirow{2}{*}{\multicolumn{2}{|c|}{$\tan \delta \mathrm{T}_{\mathrm{g}} /{ }^{\circ} \mathrm{C}$}} & \multicolumn{3}{|c|}{ Damping Temperature Field $(\tan \delta>0.3)$} \\
\hline & & & $T_{1} /{ }^{\circ} \mathrm{C}$ & $\mathrm{T}_{2} /{ }^{\circ} \mathrm{C}$ & $\Delta T^{\circ} \mathrm{C}$ \\
\hline pure-PECH/PU & 0.9064 & 15.75 & -1.1 & 33.3 & 34.4 \\
\hline $1.96 \%-\mathrm{SiO}_{2} / \mathrm{PU}$ & 0.8319 & 15.70 & -0.8 & 34.8 & 35.6 \\
\hline $4.75 \%-\mathrm{SiO}_{2} / \mathrm{PU}$ & 0.7729 & 17.50 & 0.2 & 34.8 & 34.6 \\
\hline $7.59 \%-\mathrm{SiO}_{2} / \mathrm{PU}$ & 0.7065 & 18.25 & 1.2 & 36.8 & 35.6 \\
\hline $9.74 \%-\mathrm{SiO}_{2} / \mathrm{PU}$ & 0.6761 & 21.00 & 4.4 & 38.7 & 34.3 \\
\hline
\end{tabular}

\subsection{Analysis of the Mechanism(s) of $T_{g}$ and $T_{1}$ Changes in POSS-Based Polyurethane Nanocomposites}

For the amorphous POSS-PU nanocomposite systems, the change of $T_{1}$ and $T_{\mathrm{g}}$ is closely related to the crosslinking density, molecular weight between crosslinking points and the interaction between molecular chains. For this reason, we determined the following important properties of our materials: (i) The crosslinking density of the systems, which was tested by gel extraction (see Section 2.4 for details), and (ii) the change of cohesive energy density (CED) of POSS-PU and $\mathrm{SiO}_{2}-\mathrm{PU}$ composite systems, which is used to estimate the intermolecular interaction in polymers and can be estimated by formula (2) [30,31]:

$$
\mathrm{E}=13.3 \delta^{2},
$$

where $\mathrm{E}$ is the modulus of elasticity (as determined through mechanical testing of our composites); see data in Tables 10 and 11.

Table 10. Mechanical properties and gel content of polyurethane polymers with different POSS-PECH contents.

\begin{tabular}{|c|c|c|c|c|c|c|}
\hline PU Samples & $\begin{array}{l}\text { Tensile } \\
\text { Strength } \\
\text { (MPa) }\end{array}$ & $\begin{array}{l}\text { Modulus of } \\
\text { Elasticity } \\
\text { (MPa) }\end{array}$ & $\begin{array}{c}\text { Elongation } \\
\text { at Break } \\
(\%)\end{array}$ & $\begin{array}{c}\text { Critical } \\
\text { Fracture Stress } \\
(\mathrm{MPa})\end{array}$ & $\begin{array}{c}\text { Cohesive } \\
\text { Energy Density } \\
(\mathrm{MPa})\end{array}$ & $\begin{array}{c}\text { Gel Content } \\
(\%)\end{array}$ \\
\hline Pure-PECH/PU & 8.32 & 10.90 & 142.5 & 8.32 & 0.82 & 96.28 \\
\hline $1.75 \%-P O S S 1 / \mathrm{PU}$ & 8.18 & 9.97 & 160 & 8.18 & 0.75 & 90.20 \\
\hline 4.54\%-POSS1/PU & 5.70 & 7.54 & 140 & 7.86 & 0.57 & 83.18 \\
\hline 7.57\%-POSS1/PU & 4.84 & 6.26 & 150 & 5.21 & 0.47 & 78.47 \\
\hline 9.72\%-POSS1/PU & 3.89 & 5.29 & 145 & 3.89 & 0.40 & 70.10 \\
\hline
\end{tabular}

Table 11. Mechanical properties and gel content of PU composites with different nano-SiO 2 contents.

\begin{tabular}{|c|c|c|c|c|c|c|}
\hline PU Samples & $\begin{array}{c}\text { Tensile } \\
\text { Strength } \\
(\mathrm{MPa})\end{array}$ & $\begin{array}{l}\text { Modulus of } \\
\text { Elasticity } \\
\text { (MPa) }\end{array}$ & $\begin{array}{c}\text { Elongation } \\
\text { at Break } \\
(\%)\end{array}$ & $\begin{array}{c}\text { Critical } \\
\text { Fracture Stress } \\
\text { (MPa) }\end{array}$ & $\begin{array}{c}\text { Cohesive } \\
\text { Energy Density } \\
(\mathrm{MPa})\end{array}$ & $\begin{array}{c}\text { Gel Content } \\
(\%)\end{array}$ \\
\hline Pure-PECH/PU & 8.32 & 10.90 & 142.5 & 8.32 & 0.82 & 96.28 \\
\hline $1.96 \%-\mathrm{SiO}_{2} / \mathrm{PU}$ & 5.76 & 12.18 & 94.0 & 5.76 & 0.92 & 98.24 \\
\hline $4.75 \%-\mathrm{SiO}_{2} / \mathrm{PU}$ & 6.87 & 17.00 & 86.7 & 6.87 & 1.28 & 96.67 \\
\hline $7.59 \%-\mathrm{SiO}_{2} / \mathrm{PU}$ & 10.21 & 23.93 & 84.7 & 10.21 & 1.80 & 97.39 \\
\hline $9.74 \%-\mathrm{SiO}_{2} / \mathrm{PU}$ & 15.83 & 31.93 & 102 & 15.83 & 2.40 & 96.96 \\
\hline
\end{tabular}

The analysis of data in Tables 10 and 11 highlights the following:

The gel content of the PU composite decreased with the increase of POSS1 content. This indicated that the chemical crosslinking degree of the system was also decreasing. However, $\mathrm{SiO}_{2}$ with similar content had little influence on the gel content of the system. Therefore, compared with $\mathrm{SiO}_{2}-\mathrm{PU}$ composites, the molecular chain thermal motions of the POSS-PU system increased with the increase of increasing POSS content due to the limitation of the decreased limitations of chemical and physical crosslinking decrease.

The CED of the PU composites decreased with increasing POSS1 content. The CED of the POSS-PU system decreased from $820 \mathrm{KPa}$ (for an unmodified PU) to $400 \mathrm{KPa}$ ( $9.72 \mathrm{wt} \%$ POSS1). However, the CED (a measure of the strength of molecular chain interactions) of the $\mathrm{SiO}_{2}$ composite 
system with similar content increased to $2400 \mathrm{KPa}$. The decreasing CED indicated that in the monodispersed state, even if the POSS particles content reached $9.72 \mathrm{wt} \%$, it will not hinder the thermal motion of PU molecular chains.

The influence of gel content and CED on the thermal motion ability of the molecular chains of the POSS-PU system was consistent. That is, with the increase of POSS content, chemical and physical restrictions in the system were constantly reduced. Hence, the thermal motion ability of the PU molecular chain segment was enhanced. As a result, $T_{1}$ and $T_{\mathrm{g}}$ decreased with the increasing POSS content.

\subsection{Analysis of the Damping Mechanism of the POSS-Based Polyurethane Composite System}

The damping properties of polymeric materials arise from the internal friction caused by molecular chain motions and the formation and dissociation of intermolecular hydrogen bonds. The structural chemical characteristics of our nanocomposite systems were determined through FTIR, which identifies the hydrogen bonds in the analyzed systems. For the PUs, hydrogen bonding appeared in the N-H stretching region (3500-3100 $\mathrm{cm}^{-1}$ ) and the $C=O$ stretching region $\left(1740-1710 \mathrm{~cm}^{-1}\right)$, in which two absorption peaks are observed. The spectra of the stretching vibrations of $\mathrm{N}-\mathrm{H}$ and $-\mathrm{C}=\mathrm{O}$ in polymers with different POSS-PECH contents at the same molecular weight of POSS-PECH are shown in Figure 6. As shown in Figure 6, the stretching vibration peaks of weakly hydrogen bonded $\mathrm{N}-\mathrm{H}$ and non-hydrogen bonded $-\mathrm{C}=\mathrm{O}$ appeared at $3329 \mathrm{~cm}^{-1}$ and $1727 \mathrm{~cm}^{-1}$, respectively, and the peak position did not shift with the change of POSS-PECH content.

In other words, the increase in the POSS core contents did not cause a change in the hydrogen bonding between the molecular chains. Therefore, the damping factor of the POSS-PU composite material was mainly caused by the friction between the PU molecular chain and the inorganic nano-POSS cage surface.

The fraction of interfacial area between our PECH-functionalized hybrid nanoparticles and the polymer matrix increased with increasing such POSS content. Under the action of periodic external forces, the total amount of PU molecular chains in the interfacial region that were repeatedly stripped and re-adsorbed also kept increasing, which results in the damping factor increasing with the increase of our PECH-POSS content.
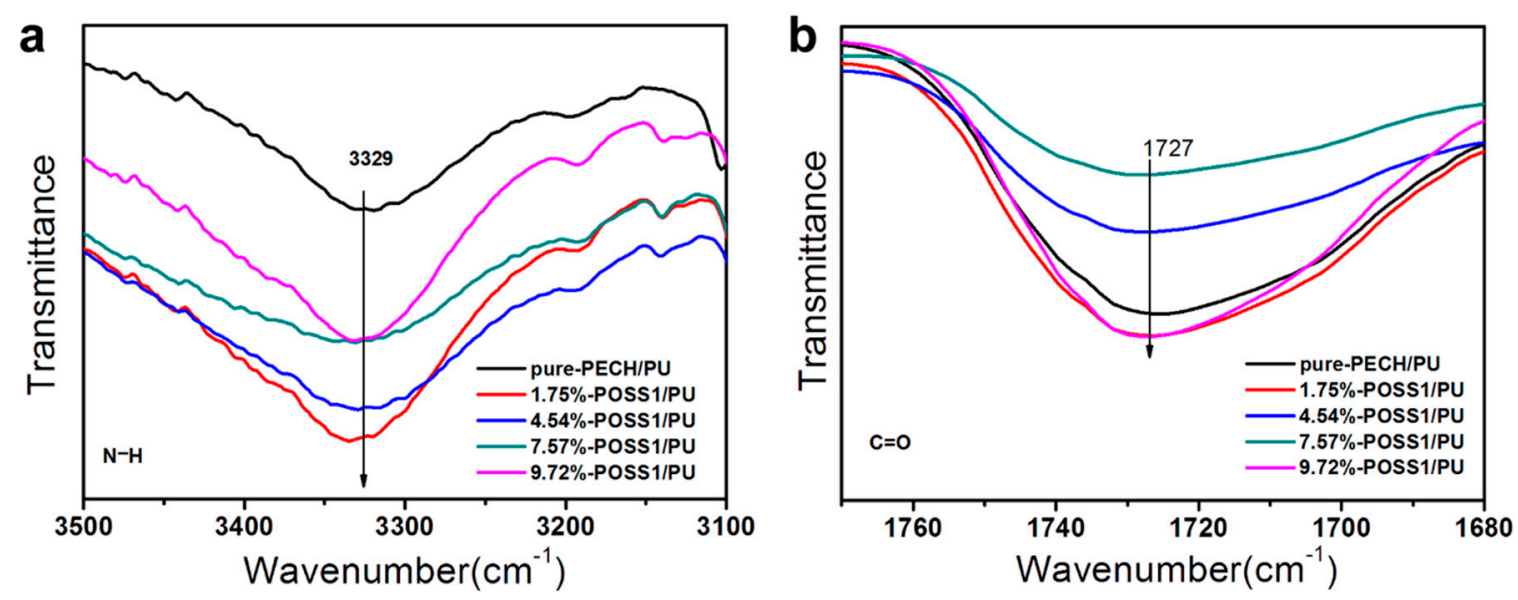

Figure 6. FTIR spectra of the $\mathrm{N}-\mathrm{H}$ stretching regions and the $\mathrm{C}=\mathrm{O}$ stretching regions of PUs with different contents of POSS-PECH.

\section{Conclusions}

Although polymers often exhibit good damping ability near the $T_{\mathrm{g}}$, they generally exhibit a relatively low $(\tan \delta$ ) and narrow $\Delta T$ because they lack extreme and continuous composition heterogeneity and thus cannot serve as damping materials in a broad temperature range. Considering the above issues, in this work we accomplished alleviating the above problems through: (i) Preparation 
of homogeneous monodispersed polymer nanocomposites utilizing bio-based PU resin as the matrix and (ii) significant broadening of the damping temperature range.

We demonstrated here that POSS surface-grafting with oligomeric chains of variable molecular weight yields liquefied hydroxyl-terminated polyepichlorohydrin with a POSS structure. The new organic-inorganic hybrid material enables facile preparation of mono-dispersed nanocomposite systems achieving (i) total dispersion of nanoparticles providing excellent polymer nanocomposite homogeneity for POSS contents in the range 1.75 to $9.75 \%$, (ii) excellent damping properties achieved through improvement of viscoelastic properties of interfacial zone achieved through shielding of inorganic (POSS) core by surface-grafted oligomeric molecular chains, and (iii) significant reduction of $T_{\mathrm{g}}$, combined with broadening of damping temperature field. The proposed approach lays the foundation for a novel means of engineering the glass transition breadth and damping properties of elastomeric nanocomposites over a broadened range of application temperatures.

Supplementary Materials: The following are available online at http:/ /www.mdpi.com/2073-4360/11/4/647/s1, Figure S1 ${ }^{29} \mathrm{Si}$ NMR spectra of POSS1-PECH Figure S2: FTIR spectra of POSS2-PECH, Figure S3: FTIR spectra of POSS3-PECH, Figure S4: FTIR spectra of POSS4-PECH, Figure S5: ${ }^{1} \mathrm{H}$ NMR spectra of POSS2-PECH, Figure S6: ${ }^{1} \mathrm{H}$ NMR spectra of POSS3-PECH, Figure S7: ${ }^{1} \mathrm{H}$ NMR spectra of POSS4-PECH, Figure S8: ${ }^{13} \mathrm{C}$ NMR spectra of POSS2-PECH, Figure S9: ${ }^{13} \mathrm{C}$ NMR spectra of POSS3-PECH, Figure S10: ${ }^{13} \mathrm{C}$ NMR spectra of POSS4-PECH, Figure S11: ATR-IR spectra of PUs with different POSS-PECH, Figure S12: ATR-IR spectra of PUs with different isocyanate index, Figure S13: ATR-IR spectra of PUs with different $\mathrm{SiO}_{2}$ content S14: (a) SEM images of 1.75\% POSS modified PU. (b) Element mapping images of Si (1.75\% POSS modified PU). (c)SEM images of $4.54 \%$ POSS modified PU. (d)Element mapping images of Si (4.54\%POSS modified PU). (e)SEM images of $7.57 \%$ POSS modified PU. (f)Element mapping images of Si (7.57\% POSS modified PU), Figure S15: (a) SEM images of $4.75 \% \mathrm{SiO}_{2}$ modified PU. (b) Element mapping images of $\mathrm{Si}\left(4.75 \% \mathrm{SiO}_{2}\right.$ modified PU). (c) $\mathrm{SEM}$ images of $7.59 \% \mathrm{SiO}_{2}$ modified PU. (d) Element mapping images of $\mathrm{Si}\left(7.59 \% \mathrm{SiO}_{2}\right.$ modified PU). (e) $\mathrm{SEM}$ images of $9.74 \% \mathrm{SiO}_{2}$ modified PU. (f) Element mapping images of $\mathrm{Si}\left(9.74 \% \mathrm{SiO}_{2}\right.$ modified PU), Figure S16: Loss factor $(\tan \delta)$ curves vs temperature for PUs with different $\mathrm{T}_{7}$-POSS contents, Figure S17: (a) SEM images of 1.77\% $\mathrm{T}_{7}$-POSS modified PU. (b) SEM images of $4.52 \% \mathrm{~T}_{7}$-POSS modified PU. (c) SEM images of $7.55 \% \mathrm{~T}_{7}$-POSS modified PU. (d) SEM images of $9.73 \%$ $\mathrm{T}_{7}$-POSS modified PU, Figure S18: TEM images of $1.77 \% \mathrm{~T}_{7}$-POSS modified PU, Figure S19: Loss factor $(\tan \delta)$ curves vs temperature for PUs with different $\mathrm{T}_{8}$-POSS contents, Figure S20: (a) SEM images of $1.76 \% \mathrm{~T}_{8}$-POSS modified PU. (b) SEM images of 4.55\% $\mathrm{T}_{8}$-POSS modified PU. (c) SEM images of 7.57\% $\mathrm{T}_{8}$-POSS modified PU. (d) SEM images of $9.75 \% \mathrm{~T}_{8}$-POSS modified PU, Figure S21: TEM images of $1.76 \% \mathrm{~T}_{8}$-POSS modified PU, Table S1: Formulations of PU compositions, Table S2: Summary of DMA data of PUs with different $\mathrm{T}_{7}$-POSS contents, Table S3: Mechanical properties and gel content of PU Composites with different $\mathrm{T}_{7}$-POSS content, Table S4: Formulations of PU compositions, Table S5: Summary of DMA data of PUs with different $\mathrm{T}_{8}$-POSS contents, Table S6: Mechanical properties and gel content of PU Composites with different $\mathrm{T}_{7}$-POSS content.

Author Contributions: Investigation, W.G. and M.L.; writing—original draft preparation, W.W.; writing—review and editing, P.D. and C.Z.; formal analysis, Y.Z. (Yingjun Zhang) and Y.Z. (Yifan Zhang); software, Y.Y.

Funding: This research received no external funding.

Acknowledgments: The authors are grateful for the financial support from the Chinese National Natural Science Foundation (Project Nos. 51603201, 51603202, 51803208).

Conflicts of Interest: The authors declare no conflict of interest.

\section{References}

1. Tjong, S.C. Structural and mechanical properties of polymernanocomposites. Mater. Sci. Eng. R. Rep. 2006, 53, 72-197. [CrossRef]

2. Krishnamoorti, R.; Vaia, R.A. Polymer nanocomposites. J. Polym. Sci. Part B Polym. Phys. 2007, 45, 3252-3256. [CrossRef]

3. Meszaros, L. Polymer matrix hybrid composites: The efficient way of improved performance. Express Polym. Lett. 2014, 8, 790. [CrossRef]

4. Lee, J.K.Y.; Chen, N.; Peng, S.J; Li, L.; Tian, L.; Thakor, N.; Ramakrishna, S. Polymer-based composites by electrospinning: Preparation \&functionalization with nanocarbons. Prog. Polym. Sc. 2018, 86, 40-84.

5. Machrafi, H.; Lebon, G.; Iorio, C.S. Effect of volume-fraction dependent agglomeration of nanoparticles on the thermal conductivity of nanocomposites: Applications to epoxy resins, filled by $\mathrm{SiO}_{2}, \mathrm{AlN}$ and $\mathrm{MgO}$ nanoparticles. Compos. Sci. Technol. 2016, 130, 78-87. [CrossRef] 
6. Lee, D.W.; Yoo, B.R. Advanced silica/polymer composites: Materials and applications. J. Ind. Eng. Chem. 2016, 38, 1-12. [CrossRef]

7. Chruściel, J.J.; Leśniak, E. Modification of epoxy resins with functional silanes, polysiloxanes, silsesquioxanes, silica and silicates. Prog. Polym. Sci. 2015, 41, 67-121. [CrossRef]

8. Mittal, G.; Dhand, V.; Rhee, K.Y.; Park, S.J.; Lee, W.R. A review on carbon nanotubes and graphene as fillers in reinforced polymer nanocomposites. J. Ind. Eng. Chem. 2015, 21, 11-25. [CrossRef]

9. Zhou, X.Q.; Yu, D.Y.; Shao, X.Y.; Zhang, S.Q.; Wang, S. Research and applications of viscoelastic vibration damping materials: A review. Compos. Struct. 2016, 136, 460-480. [CrossRef]

10. Sun, L.Y.; Gibson, R.F.; Gordaninejad, F.; Suhr, J. Energy absorption capability of nanocomposites: A review. Compos. Sci. Technol. 2009, 69, 2392-2409. [CrossRef]

11. Zhu, G.L.; Han, D.; Yuan, Y.; Chen, F.; Fu, Q. Improving Damping Properties and Thermal Stability of Epoxy/Polyurethane Grafted Copolymer by Adding Glycidyl POSS. Chin. J. Polym. Sci. 2018, 36, 1297-1302. [CrossRef]

12. Ristić, I.S.; Simendić, J.B.; Krakovsky, I.; Valentova, H.; Radičević, R.; Cakić, S.; Nikolić, N. The properties of polyurethane hybrid materials based on castor oil. Chin. Mater. Chem. Phys. 2012, 132, 74-81. [CrossRef]

13. Sahoo, S.; Kalita, H.; Mohanty, S.; Nayak, S.K. Shear Strength and Morphological Study of Polyurethane-OMMT Clay Nanocomposite Adhesive Derived from Vegetable Oil-Based Constituents. J. Renew. Mater. 2018, 6, 117-125. [CrossRef]

14. Li, Y.; Jiao, H.Y.; Pan, G.Q. Mechanical and damping properties of carbon nanotube-modified polyisobutylene-based polyurethane composites. J. Compos. Mater. 2016, 50, 929-936. [CrossRef]

15. Michael, E.M.; Anish, T.; Phillip, M.D. General strategies for nanoparticle dispersion. Science 2006, 311, 1740-1743.

16. Gupta, S.; Zhang, Q.L.; Emrick, T. Entropy-driven segregation of nanoparticles to cracks in multilayered composite polymer structures. Nat. Mater. 2006, 5, 229-233. [CrossRef]

17. Anna, C.B.; Emrick, T.; Russell, T.P. Nanoparticle polymer compositesn: Where two small worlds meet. Science 2006, 314, 1107-1110.

18. Guo, Z.R.; Chang, T.C.; Guo, X.M. Thermal-Induced Edge Barriers and Forces in Interlayer Interaction of Concentric Carbon Nanotubes. Phys. Rev. Lett. 2011, 107, 105502. [CrossRef]

19. Chang, T.C.; Zhang, H.W.; Guo, Z.R. Nanoscale directional motion towards regions of higher stiffness. Phys. Rev. Lett. 2015, 114, 015504. [CrossRef] [PubMed]

20. Li, J.X.; Zhang, H.W.; Guo, Z.R.; Chang, T.C. Edge Forces in Contacting Graphene Layers. J. Appl. Mech. 2015, 82, 101011. [CrossRef]

21. Suhr, J.; Koratkar, N.; Keblinski, P.; Ajayan, P. Viscoelasticity in carbon nanotube composites. Compos. Sci. Technol. 2005, 4, 134-137. [CrossRef]

22. Chen, S.; Wang, Q.; Wang, T. Damping, thermal, and mechanical properties of carbon nanotubes modified castor oilbased polyurethane/epoxy interpenetrating polymer network composites. Mater. Design. 2012, 38, 47-52. [CrossRef]

23. Chen, S.; Wang, Q.; Wang, T. Damping, thermal, and mechanical properties of montmorillonite modified castor oilbased polyurethane/epoxy graft IPN composites. Mater. Chem. Phys. 2011, 130, 680-684. [CrossRef]

24. Chen, S.; Wang, Q.; Wang, T.; Pei, X. Preparation, damping and thermal properties of potassium titanate whiskers filled castor oil-based polyurethane/epoxy interpenetrating polymer network composites. Compos. Sci. Technol. 2011, 32, 803-807. [CrossRef]

25. Blanco, I.; Bottino, F.A.; Cicala, G.; Cozzo, G.; Latteri, A.; Recca, A. Synthesis and thermal characterization of new dumbbell shaped POSS/PS nanocomposites: Influence of the symmetrical structure of the nanoparticles on the dispersion/aggregation in the polymer matrix. Polym. Compos. 2014, 36, 1394-1400. [CrossRef]

26. Blanco, I. The Rediscovery of POSS: A Molecule Rather than a Filler. Polymers 2018, 10, 904. [CrossRef]

27. Tanaka, K.; Adachi, S.; Chujo, Y. Structure-property relationship of octa-substituted POSS in thermal and mechanical reinforcements of conventional polymers. J. Polym. Sci. 2009, 47, 5690-5697. [CrossRef]

28. Trakulsujaritchok, T.; Hourston, D.J. Damping characteristics and mechanical properties of silica Wlled PUR/PEMA simultaneous interpenetrating polymer networks. Eur. Pol. J. 2006, 42, 2968-2976. [CrossRef]

29. Zhang, H.W.; Wang, B.; Li, H.T.; Yan, J.; Wang, J.Y. Synthesis and characterization of nanocomposites of silicon dioxide and polyurethane and epoxy resin interpenetrating network. Polym. Int. 2003, 52, 1493-1497. [CrossRef] 
30. Robert, M.E.; Tyler, R.L.; Erich, D.B.; Joseph, L.L.; Timothy, W.S. Mechanics and nanovoid nucleation dynamics: Effects of polar functi- onality in glassy polymer networks. Soft Matter 2018, 14, 8895-8911.

31. Fu, Z. Strength theory of polymer materials. In Strength and Failure Behavior of Polymer Materials, 1st ed.; Chemical Industry Press: Beijing China, 2005; pp. 41-42. 